\title{
ATP-Activated Channels in Rat and Bullfrog Sensory Neurons: Current-Voltage Relation and Single-Channel Behavior
}

\author{
Bruce P. Bean, Christopher A. Williams, and Paul W. Ceelen \\ Department of Neurobiology, Harvard Medical School, Boston, Massachusetts 02115
}

Ionic currents activated by extracellular adenosine $5^{\prime}$-triphosphate (ATP) were studied in voltage-clamped dorsal root ganglion neurons from rats and bullfrogs. Under quasiphysiological ionic conditions, ATP-activated current reversed near $0 \mathrm{mV}$ and showed strong inward rectification. Strong inward rectification was maintained even in symmetric solutions of divalent-free $C s$ glutamate. Examined with a resolution of $10 \mathrm{~s}$ of microseconds, the rectification was instantaneous. Inward current was greatly reduced when N-methyl-D-glucamine was substituted for external Na. ATP. activated inward currents could be recorded with $\mathrm{Ca}$ as the only external cation; estimated from reversal potentials, the ratio of $\mathrm{Ca}$ to $\mathrm{Na}$ permeability is about $\mathbf{0 . 3}$. Unitary channel activity could be recorded when ATP was applied to outsideout patches. When activated, a single channel flickered rapidly, with a mean current of about $0.5 \mathrm{pA}$ at $-100 \mathrm{mV}$. Large concentrations of ATP put the channel in the activated, flickery condition virtually all the time, while at lower concentrations, periods of flickering were interspersed with closures. Analysis of whole-cell current fluctuations showed precisely the characteristics expected if such channels underlie the macroscopic currents.

In the first voltage-clamp study of adenosine 5'-triphosphate (ATP)-activated currents in sensory neurons, Krishtal et al. (1983) found that the inward current induced by ATP applied at negative membrane potentials was carried mainly by $\mathrm{Na}$ ions. With $\mathrm{K}$ as the main internal cation, the ATP-activated current reversed near $0 \mathrm{mV}$, suggesting equal permeabilities of $\mathrm{K}$ and $\mathrm{Na}$. However, the current showed strong rectification, with outward currents very hard to resolve. Since then, ATP-activated currents have also been studied in a variety of smooth (Benham and Tsien, 1987; Benham et al., 1987; Nakazawa and Matsuki, 1987; Fricl, 1988), cardiac (Fricl and Bcan, 1988), and skeletal muscle cells (Hume and Honig, 1986). Most of these currents are similar to neuronal currents in being cation-selective and reversing near $0 \mathrm{mV}$. However, the shape of the current-voltage relation is quite different in different preparations, for example being nearly linear in cardiac atrial cells (Friel and Bean, 1988).

Single-channel recordings have recently been reported for ATPactivated channels in ear artery muscle (Benham and Tsien,

Received Jan. 17, 1989; revised June 13, 1989; accepted June 21, 1989.

Supported by grants from the NIH (HL-35034) and the Rita Allen Foundation. B.P.B. is an Established Investigator of the American Heart Association. C.A.W.'s work, done while he was a medical student at the University of Iowa, was supported by a fellowship from the Commonwealth Medical Fund.

Correspondence should be addressed to Bruce P. Bean, Department of Neurobiology, Harvard Medical School, 220 Longwood Avenue, Boston MA 02115. Copyright (C) 1990 Society for Neuroscience 0270-6474/90/010011-09\$02.00/0
1987) and vas deferens muscle (Nakazawa and Matsuki, 1987); in both cases, single-channel currents with quasi-physiological ionic conditions are roughly $1 \mathrm{pA}$ at potentials of -70 to -100 $\mathrm{mV}$. Already it seems likely that single-channel currents are different in some other cell types; in cardiac atrial cells (Friel and Bean, 1988), noise analysis suggests that unitary currents are at least an order of magnitude lower, and unitary currents are likely also very small in cultured chick skeletal muscle (Hume and Honig, 1986).

The purpose of the work described in this paper was to learn more about ion permeation in ATP-activated channels in sensory neurons and to attempt to record single ATP-activated channels. We found that inward rectification is present under a variety of ionic conditions, including with symmetric divalentfree solutions. $\mathrm{Cs}, \mathrm{Na}$, and $\mathrm{K}$ are about equally permeant; $\mathrm{Ca}$ is somewhat less permeant, while $N$-methyl-D-glucamine (NMDG) is nearly impermeant. Single-channel currents could be recorded in outside-out patches. The channels show such rapid flickering when activated that fully open levels are not well defined. The voltage dependence of mean current through activated channels has the same shape as macroscopic currentvoltage curves.

A preliminary report of this work has appeared (Bean et al., 1988).

\section{Materials and Methods}

The methods and solutions were identical to those in the previous paper. In the noise-analysis experiments, efforts were made to improve the bandwidth of the recorded current signal. In whole-cell recording with a single pipette, the signal is effectively low-pass filtered with a timeconstant of $R_{s} C_{\text {cell }}$ where $R_{s}$ is the effective series resistance from the pipette (which can be minimized by using series resistance compensation) and $C_{\text {cell }}$ is the cell capacitance. We therefore used relatively low resistance pipettes $(1-4 \mathrm{M} \Omega)$ and as much series resistance compensation as possible without producing ringing of the capacitative transient (usually $80-90 \%$ ). In these experiments, $R_{s} C_{\text {cell }}$ was typically $40-150 \mu \mathrm{sec}$ after series resistance compensation, corresponding to filtering at $1-3$ $\mathrm{kHz}$.

\section{Results}

\section{Current-voltage relation}

Figure 1 shows the effect of ATP on current at different voltages in a bullfrog DRG neuron studied under quasi-physiological conditions (high $\mathrm{K}$ inside, high $\mathrm{Na}$ outside). Pulses lasting 50 $\mathrm{msec}$ were given from a holding potential of $-50 \mathrm{mV}$. The application of $100 \mu \mathrm{M}$ ATP caused a small outward shift of the current at $+110 \mathrm{mV}$, a small inward shift of the holding current at $-50 \mathrm{mV}$, and a large inward shift of the current at -130 $\mathrm{mV}$. It was found to be crucial to make measurements of the effects of ATP within seconds after its application. With longer 
A
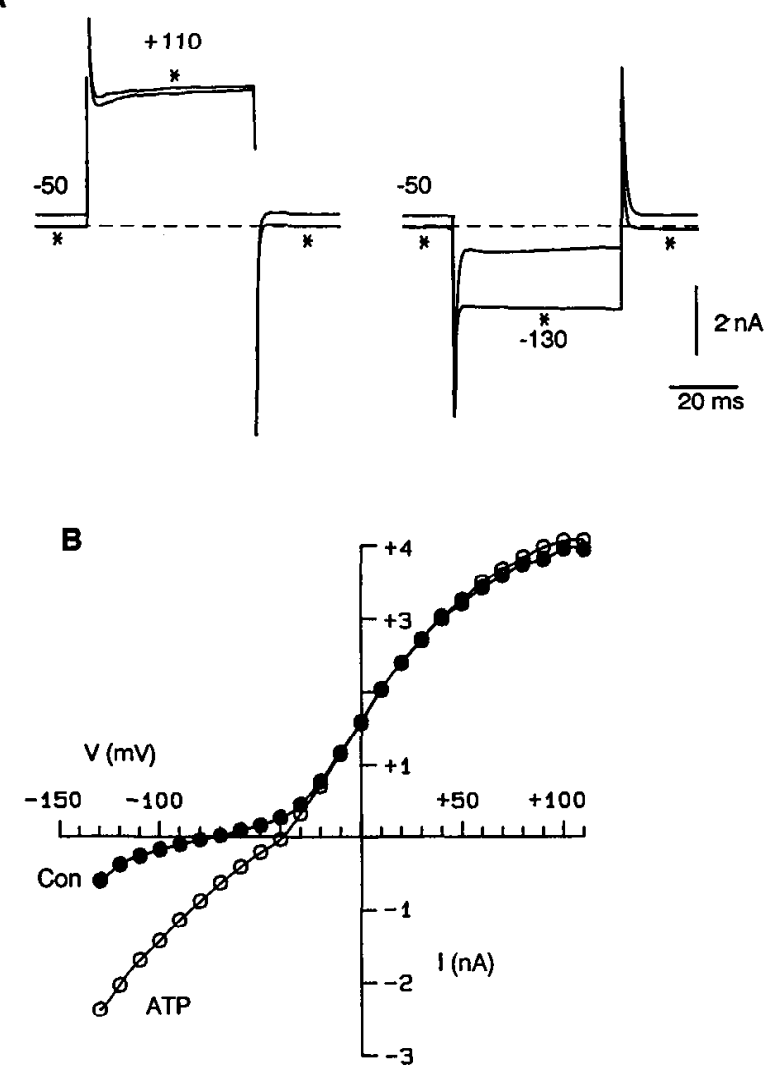

Figure 1. Effect of ATP on current at different voltages. Complete current-voltage curves were determined every $2.5 \mathrm{sec}$ by application of $50 \mathrm{msec}$ pulses (spanning the range $-130-+110 \mathrm{mV}$ in $10 \mathrm{mV}$ increments) delivered every $100 \mathrm{msec}$ from a holding potential of $-50 \mathrm{mV}$. $A$, Currents at +110 and $-130 \mathrm{mV}$ obtained just before and a few seconds after (asterisks) application of ATP. B, Current (measured at the end of the $50 \mathrm{msec}$ voltage step) as a function of voltage, measured just before and $0.2-2.7 \mathrm{sec}$ after application of $100 \mu \mathrm{M}$ ATP. K glutamate internal solution. Cell W24B.

applications, the current during pulses to very positive potentials actually decreased relative to control levels; a variety of experiments suggested that this decrease was due to block of voltagedependent $\mathrm{K}$ channels by internal $\mathrm{Na}$ (Hille, 1975; French and Wells, 1977; Marty, 1983) entering through the ATP-activated channels. Figure $1 B$ shows the current-voltage relation for the cell before and after application of $100 \mu \mathrm{M}$ ATP. The zerocurrent potential (i.e., the cell's resting potential) changed from $-70 \mathrm{mV}$ in control to $-37 \mathrm{mV}$ in ATP, showing that the ATP would have depolarized the cell.

Figure 2 shows the current-voltage relation for the ATP-induced current determined with 4 different sets of ionic conditions. In each case, ATP-induced current at each potential was determined by subtracting control currents from those obtained $1-2 \mathrm{sec}$ after applying $100 \mu \mathrm{M}$ ATP. With the quasi-physiological ionic conditions of Figure 1, the current activated by ATP showed strong inward rectification, with large inward currents and small outward currents (Fig. $2 A$ ). The apparent reversal potential for the ATP-activated current was about $+15 \mathrm{mV}$. However, the currents were so small in the range of -20 to $+50 \mathrm{mV}$ that it is impossible to feel confident about this value, especially because the block of outward $\mathrm{K}$ currents by accumulating internal $\mathrm{Na}$ would tend to depress the measured outward currents and artifactually shift the reversal potential in positive direction.
A

$K$ glut // Tyrode's

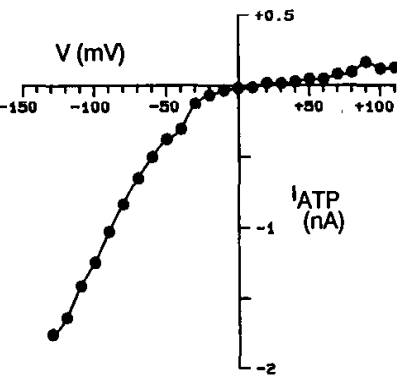

B Cs glut // Tyrode's

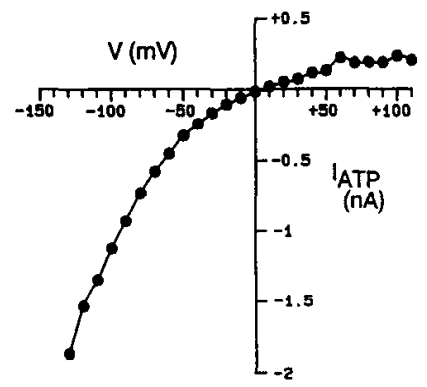

C Mg-free Cs glut // Tyrode's

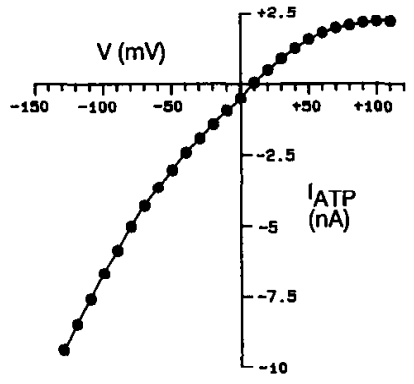

D Mg-free Cs glut both sides

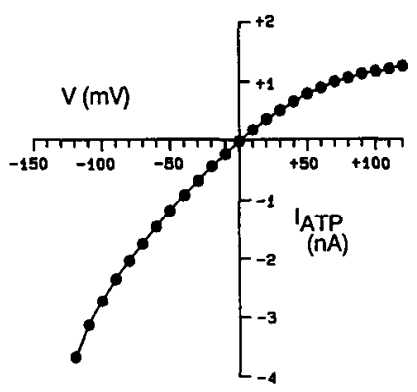

Figure 2. Current-voltage relation for ATP-elicited current under different ionic conditions. The ATP-elicited current was obtained by subtraction of currents before and after application of ATP, with currentvoltage curves determined every $2.5 \mathrm{sec}$ as in Figure 1. A, ATP-elicited current obtained from subtraction of the current-voltage relations in Figure $1 B$, with "K glutamate solution" internally and Tyrode's solution externally (see Materials and Methods of preceding paper for solution compositions). $B$, ATP-elicited current determined identically, except with Cs replacing internal $\mathrm{K}$ ions. Cell W33E, $30 \mu \mathrm{M}$. $C$, Current-voltage relation with $\mathrm{Mg}$ omitted from the internal solution [(in mM) $140 \mathrm{Cs}$ glutamate, $10 \mathrm{Cs}_{2}$ EGTA, $10 \mathrm{HEPES}$, pH 7.4 with CsOH]. $D$, Currentvoltage relation with $\mathrm{Mg}$-free Cs glutamate solution (same as the internal solution in $C$ ) both internally and externally. Same cell as in $C$. Voltages were corrected for junction potentials in all cases (see Materials and Methods of previous paper).

The current-voltage relation was not much different when Cs replaced $\mathrm{K}$ as the main internal cation; the reversal potential was near $0 \mathrm{mV}$, and there was strong inward rectification (Fig. $2 B$ ). With Cs as the main internal cation, outward currents in the absence of ATP were much smaller than with $K$, and the reversal potential was better defined. In 11 bullfrog neurons with these ionic conditions, the reversal potential for ATP-activated current was $+11 \pm 4 \mathrm{mV}$. The current-voltage relation had an identical shape in rat neurons studied under the same conditions; in 7 rat neurons, the reversal potential was $+8 \pm 4$ $\mathrm{mV}$.

One possibility is that inward rectification like that in Figure 2, $A, B$ is due to block of outward currents by the $5 \mathrm{~mm} \mathrm{Mg}$ that was present in the internal solutions. Figure $2 C$ shows results from a cell studied with ionic conditions similar to those in Figure $2 B$ but with internal $\mathrm{Mg}$ omitted. Removing internal $\mathrm{Mg}$ reduced the severity of the rectification but did not eliminate it. In fact, the inward-rectifying property of the current persisted even with identical divalent-free Cs glutamate solutions inside and outside the cell (Fig. 2D); the current elicited at $-120 \mathrm{mV}$ was about 3 times as large as that at $+120 \mathrm{mV}$ despite the equal driving forces. 


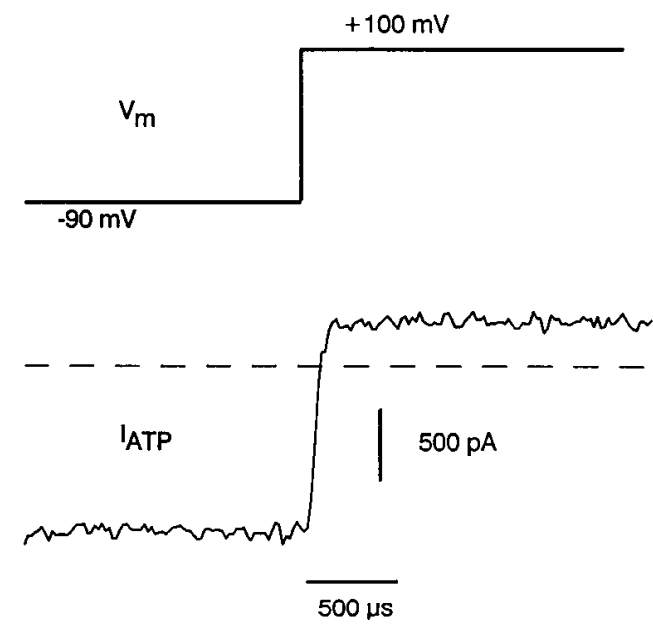

Figure 3. Rapid voltage jump during ATP-activated current. The current trace is the difference of currents recorded during the indicated voltage step just before and $3 \mathrm{sec}$ after the application of $100 \mu \mathrm{M}$ ATP. The current was filtered at $10 \mathrm{kHz}$ and sampled every $20 \mu \mathrm{sec}$. Series resistance compensation for $65 \%$ of a measured series resistance of 5.2 $\mathrm{M} \Omega$; cell capacitance, $22 \mathrm{pF}$. The expected settling time constant of the voltage is $(0.35 \cdot 5.2 \mathrm{M} \Omega \cdot 22 \mathrm{pF})=40 \mu \mathrm{sec}$; this was exactly the time constant with which the current settled during the voltage jump. Internal solution: Mg-free Cs-glutamate; external solution (in $\mathrm{mM}$ ): $160 \mathrm{NaCl}, 2$ $\mathrm{CaCl}_{2}, 10$ HEPES, pH 7.4 with $\mathrm{NaOH}$. Cell K12A, $36 \mu \mathrm{m}$.

Is the rectification of the ATP-activated current due to voltage-dependent gating of the channel or to the properties of ion permeation in the channel? An effort was made to resolve possible voltage-dependent relaxations of current (Fig. 3). A voltage step from -90 to $+100 \mathrm{mV}$ was given in a cell studied with a relatively low resistance pipette (and with series resistance compensation) in order to maximize the speed of the voltage jump seen at the membrane (calculated time constant $40 \mu \mathrm{sec}$ ). The ATP-activated current, obtained by subtraction of current before and after ATP application, changed smoothly and rapidly during the voltage jump. There was no overshoot or relaxation of current at $+100 \mathrm{mV}$. This result is consistent with rectification being an instantaneous property of ion permeation in the channel. However, another possibility is that rectification arises from very fast voltage-dependent gating of the channel that is complete within 10 s of microseconds during the change in voltage.

Figure 4 shows the effect of replacing external $\mathrm{Na}$ with the large cation NMDG. Figure $4 A$ shows current-voltage curves determined with normal external Tyrode's solution before and after applying ATP to a bullfrog DRG neuron. As expected, ATP induced a current that reversed at $0 \mathrm{mV}$ and showed strong inward rectification. Then, the external solution was changed to one in which the $\mathrm{Na}$ was replaced with NMDG. Now, ATP induced a much smaller inward current at negative potentials, and the reversal potential shifted to $-50 \mathrm{mV}$ (Fig. $4 B$ ). Howcver, there was little change in the outward current induced by ATP in the range of $+50-+90 \mathrm{mV}$. These are exactly the changes expected if the Na permeability of the ATP-induced conductance is relatively high. The change in the reversal potential (and lack of any large effect on outward current) are consistent with NMDG acting as an impermeant ion rather than a blocker.

It was striking that although the ATP-induced inward current was greatly reduced by NMDG substitution in Figure $4 B$, it was not eliminated. The possibility that the remaining current was
A Tyrode's $\quad$ B Na-free Tyrode's

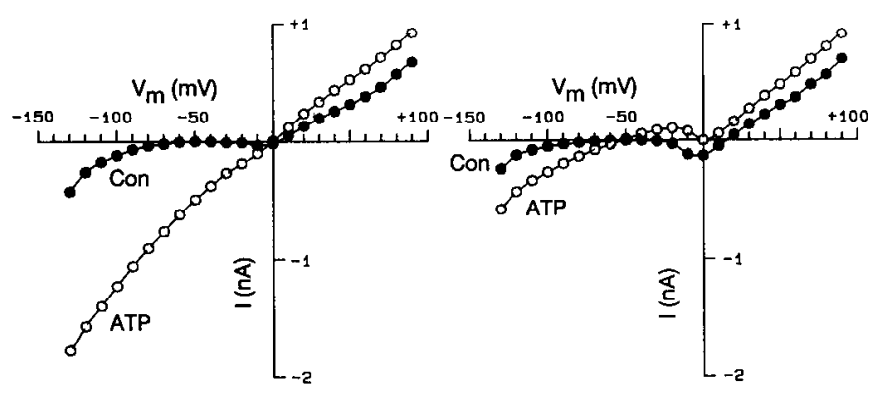

C

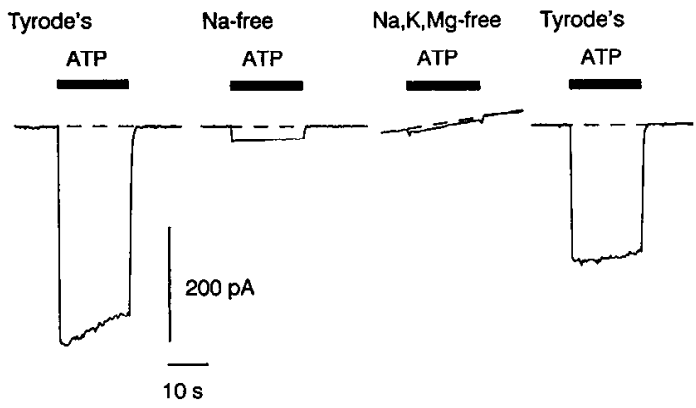

Figure 4. Effects of cation substitution in the external solution. A, ATPinduced change in $I-V$ curve (determined using fast $I-V$ protocol) in a bullfrog neuron with Cs-glutamate internal solution and normal Tyrode's solution externally. [ATP] $=100 \mu \mathrm{M} . B$, Effect of ATP in the same cell after changing to an external solution in which NMDG replaced $\mathrm{Na}$ [(in mM) $150 \mathrm{NMDG}, 4 \mathrm{KCl}, 2 \mathrm{CaCl}_{2}, 2 \mathrm{MgCl}_{2}, 10$ glucose, 10 HEPES, pH adjusted to 7.40 with $\mathrm{HCl}$ ]. Cell W32A. $C$, Effect of substituting NMDG for $\mathrm{Na}$ alone (solution as in $B$ ) or for $\mathrm{Na}, \mathrm{K}$, and $\mathrm{Mg}$ [(in mM) $157 \mathrm{NMDG}, 2 \mathrm{CaCl}_{2}, 10$ glucose, 10 HEPES, $\mathrm{pH}$ adjusted to 7.4 with $\mathrm{HCl}$ ] on current elicited by $100 \mu \mathrm{M} \mathrm{ATP}$ at $-80 \mathrm{mV}$; same cell as in $A$ and $B$. After changing to solution in which $\mathrm{Na}, \mathrm{K}$, and $\mathrm{Mg}$ were removed, there was an initial inward shift of current followed by a slow relaxation outward. In each case, a dashed baseline is drawn at the current level before application of ATP; the baseline in the third panel is shifted up by about $100 \mathrm{pA}$ and is drawn with a sloping baseline to account for the ongoing relaxation of current.

carried by the $\mathrm{K}(2 \mathrm{~mm}), \mathrm{Mg}(2 \mathrm{~mm})$, or $\mathrm{Ca}(2 \mathrm{~mm})$ remaining in the Na-free Tyrode's was examined in the experiment shown in Figure 4C. Substitution of NMDG for $\mathrm{Na}$ reduced the inward current (recorded at a holding potential of $-80 \mathrm{mV}$ ) to about $8 \%$ of control. Further substitution of NMDG for $\mathrm{K}$ and $\mathrm{Mg}$ resulted in suppression of most-but not quite all-of the remaining current; the ATP-activated current was about $2 \%$ of control in this solution. Returning to Tyrode's solution confirmed that the changes in current were caused mainly by the ionic substitutions and not by run-down or desensitization of the current.

The very small ATP-activated current that remained when NMDG replaced all external cations except $2 \mathrm{~mm}$ Ca could be due to permeability of $\mathrm{Ca}$, a small permeability of NMDG, or both. It is obviously of interest to know whether the ATPactivated channel is permeable to $\mathrm{Ca}$ since entry of $\mathrm{Ca}$ into cells is important for so many physiological processes. The permeability of Ca was studied directly by applying ATP in an external solution in which $\mathrm{Ca}$ was the only cation (at $113 \mathrm{~mm}$ ). Substantial inward currents could be elicited by ATP under thesc conditions (Fig. 5). The current at negative potentials carried 
A

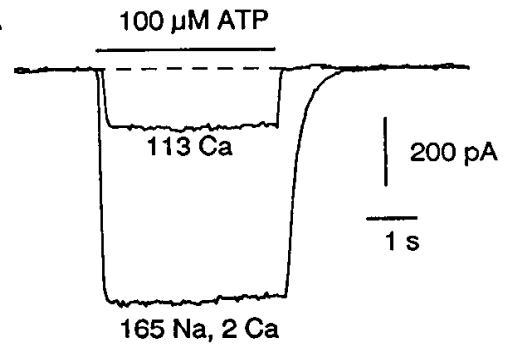

B

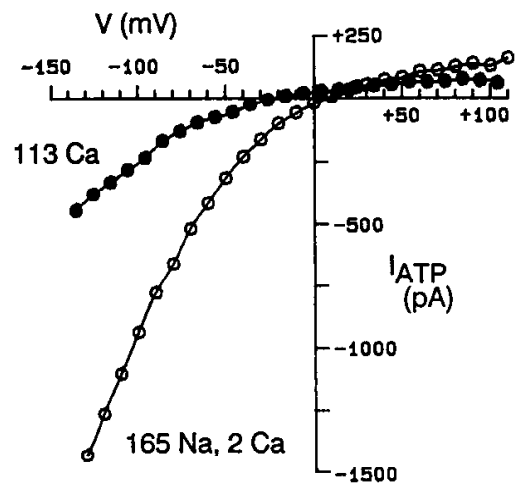

C

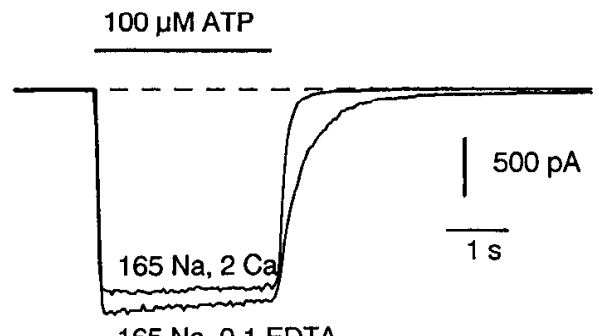

$165 \mathrm{Na}, 0.1$ EDTA

Figure 5. Ca permeation and block in the ATP-activated channel. $A$, Comparison of currents activated in the same bullfrog DRG neuron by $100 \mu \mathrm{M}$ ATP with an external solution (in $\mathrm{mM}$ ) of $160 \mathrm{NaCl}, 2 \mathrm{CaCl}_{2}$, 10 HEPES (pH 7.4 with $\mathrm{NaOH}$ ) or $110 \mathrm{CaCl}_{2}, 10$ HEPES (pH 7.4 with $\mathrm{CaOH}_{2}$ ). The membrane potential was $-80 \mathrm{mV}$ with the first solution and $-87 \mathrm{mV}$ with the second (taking account of junction potentials). Internal solution: $\mathrm{Mg}$-free Cs-glutamate. Cell K05A, $35 \mu \mathrm{m}$. B, Currentvoltage relation for ATP-activated current with external solutions of isotonic $\mathrm{CaCl}_{2}$ or $165 \mathrm{~mm} \mathrm{Na}$ and $2 \mathrm{mM} \mathrm{Ca}$. Same cell and solutions as in $A$. Voltages corrected for junction potentials. $C$, Comparison of ATP-activated currrent with external solutions (in mM) of $165 \mathrm{NaCl}, 2$ $\mathrm{CaCl}_{2}, 10$ HEPES ( $\mathrm{pH} 7.4$ with $\mathrm{NaOH}$ ) or $165 \mathrm{NaCl}, 0.1$ EDTA, 10 HEPES (pH 7.4 with $\mathrm{NaOH}$ ). The record without $\mathrm{Ca}$ was obtained second to ensure that the increase in size was not due to run-down of the current. Internal solution: Mg-free Cs-glutamate. Cell K06A, $50 \mu \mathrm{m}$.

by $113 \mathrm{~mm} \mathrm{Ca}$ was about $25 \%$ of that carried by $165 \mathrm{Na}$ and 2 $\mathrm{Ca}$ in the same cell (Fig. $5 A$ ). In a total of 5 cells studied under the same conditions, current carried by $113 \mathrm{Ca}$ was $27 \pm 2 \%$ of that carried by $165 \mathrm{~mm} \mathrm{Na}$ and $2 \mathrm{~mm} \mathrm{Ca}$.

The reversal potential for the ATP-activated current was more negative with $\mathrm{Ca}$ as the external charge carrier than with $\mathrm{Na}$ as the predominant charge carrier (Fig. $5 B$ ). In a total of 5 cells studied with $165 \mathrm{~mm}$ Cs internally, the reversal potential with $113 \mathrm{~mm} \mathrm{Ca}$ externally was $-16 \pm 3 \mathrm{mV}$, while that with 165 $\mathrm{Na}, 2 \mathrm{Ca}$ externally was $-1 \pm 2 \mathrm{mV}$. These reversal potentials can be used to estimate the permeability of $\mathrm{Ca}$ relative to $\mathrm{Na}$
Rat DRG

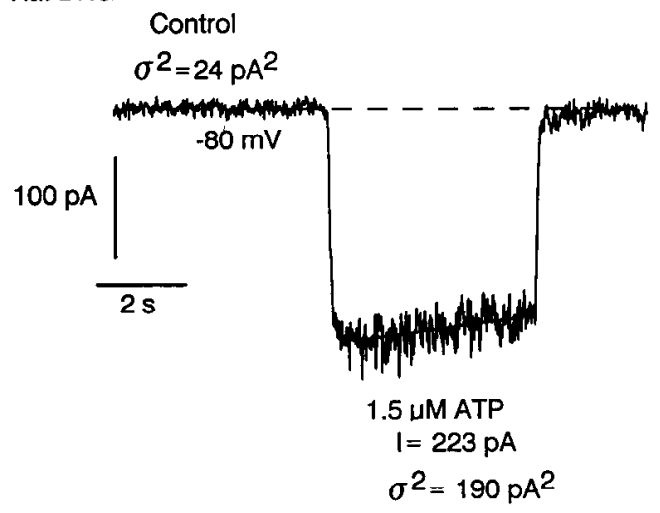

Figure 6. Fluctuations in ATP-activated current in a rat DRG neuron. Variance was calculated over a 4 sec interval in control. Variance in the presence of $1.5 \mu \mathrm{M}$ ATP was calculated over a $4 \mathrm{sec}$ interval after subtraction of a straight line to correct for steady desensitization. Filtered at $3 \mathrm{kHz}$ ( $-3 \mathrm{~dB}, 4$-pole Bessel); 2 msec sampling interval. Csglutamate internal solution. Cell W77B, 10-d-old rat, $18 \mu \mathrm{m}$.

and Cs (whose permeabilities are nearly equal based on the reversal potential of $0 \mathrm{mV}$ with internal Cs and external $\mathrm{Na}$ ). Using the version of the Goldman-Hodgkin-Katz equation introduced by Fatt and Ginshorg (1958), the reversal potential of $-16 \mathrm{mV}$ with $\mathrm{Ca}$ versus $\mathrm{Cs}$ leads to an estimate of $P_{\mathrm{Ca}} / P_{\mathrm{Cs}}$ of 0.3 (assuming activity coefficients of 0.25 for $\mathrm{Ca}$ and 0.75 for Cs). The accuracy of the calculation is suspect on every level, from the invalid assumptions underlying the Goldman-Hodgkin-Katz equation to the neglect of probable surface potentials. Nonetheless, a $P_{\mathrm{Ca}} / P_{\mathrm{Na}}$ of about 0.3 corresponds reasonably well with the observed change in current magnitudes in Figure $5 \mathrm{~A}$.

When $2 \mathrm{~mm}$ Ca was removed from an external solution of $165 \mathrm{~mm} \mathrm{Na}$, with the addition of $100 \mu \mathrm{M}$ EDTA to chelate contaminating $\mathrm{Ca}$, the ATP-activated current actually increased slightly (Fig. 5C). In repetitions of this experiment in 4 cells, the current upon removal of $\mathrm{Ca}$ increased by an average of $9 \pm$ $0.6 \%$. The small increase in current could reflect a higher concentration of $\mathrm{Na}$ at the external membrane surface duc to rcduced screening of negative surface charge.

\section{Fluctuation analysis}

Whole-cell currents induced by ATP were accompanied by a clear increase in fluctutations in current. Assuming that the macroscopic current arises from identical, independent channels, probability theory (see Neher and Stevens, 1977) predicts that the unitary current is related to the mean current and its variance by

$$
i=\sigma^{2} /[I(1-p)]
$$

where $\sigma^{2}$ is the variance, $I$ is the mean current, and $p$ is the probability of each channel being open. As long as $p$ is small, then the unitary current is nearly equal to the variance divided by the mean.

Figure 6 shows a current record used for cstimation of unitary current in a rat DRG neuron. A low concentration of ATP (1.5 $\mu \mathrm{M})$ was used to ensure that the probability of channels being open was relatively small (see previous paper), so that the unitary current could be estimated by the variance/current ratio. In this experiment, ATP elicited a mean current of $223 \mathrm{pA}$. The fluctuation of current around the mean increased compared with control; the variance of the current increased from $24 \mathrm{pA}^{2}$ in 
frog DAG
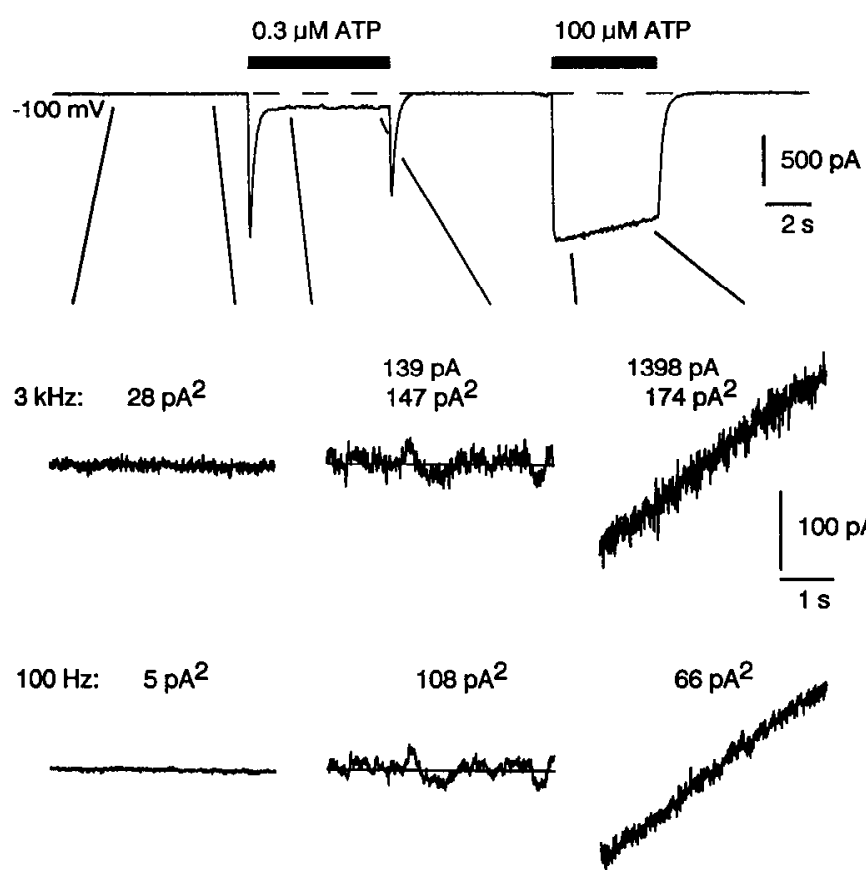

Figure 7. Fluctuations in the ATP-activated current in a bullfrog neuron. Top trace, Continuous recording of current at a holding potential of $-100 \mathrm{mV}$ before, during, and after application of 0.3 and $100 \mu \mathrm{M}$ ATP. (The transient spikes of current before and after $0.3 \mu \mathrm{M}$ ATP resulted from exposure to the general bath solution, which was stagnant and contained $>0.3 \mu \mathrm{M}$ ATP, while the cell was moved between pipes containing control and $0.3 \mu \mathrm{M}$ ATP solutions.) Middle traces, Current in control, with $0.3 \mu \mathrm{M}$ ATP and with $100 \mu \mathrm{M}$ ATP at higher gain. Filtered with a corner frequency of $3 \mathrm{kH} /(-3 \mathrm{~dB}, 8$-pole Bessel). Numbers above traces give inward current relative to control $(\mathrm{pA})$ or variance $\left(\mathrm{pA}^{2}\right)$ calculated over the indicated interval after subtracting straight lines fit to the current. Bottom traces, Same, but refiltered at $100 \mathrm{~Hz}$ to remove high frequency components. Cs-glutamate internal solution. Cell W33G, $25 \mu \mathrm{m}$

control to $190 \mathrm{pA}^{2}$ in the presence of ATP. Thus, the mean and variance of the ATP-induced current are $223 \mathrm{pA}$ and $166 \mathrm{pA}^{2}$, respectively, yielding an estimated unitary current of $0.74 \mathrm{pA}$.

Similar results were obtained in experiments on bullfrog DRG neurons. Figure 7 shows an example. Application of a low concentration of ATP $(0.3 \mu \mathrm{M})$ induced a current of $139 \mathrm{pA}$ and an increase of variance of $119 \mathrm{pA}^{2}$ (measured with a bandwidth of $3 \mathrm{kHz}$ ), yielding an estimate of $0.86 \mathrm{pA}$ for unitary current. In bullfrog neurons, it was also possible to examine fluctuations in current at high ATP concentrations because of the slow desensitization compared with rat neurons. As expected, $100 \mu \mathrm{M}$ ATP elicited a much larger current than that activated by 0.3 $\mu \mathrm{M}$. However, the increase in variance with $100 \mu \mathrm{M}$ ATP (calculated after subtraction of a fitted straight line to take account of the steady decline from desensitization) was not much more than that with $0.3 \mu \mathrm{M}$ ATP, despite the fact that the current was 10 times larger. There was also a qualitative difference in the appearance of the fluctuations in the currents elicited by 0.3 and $100 \mu \mathrm{M}$; the current activated by $100 \mu \mathrm{M}$ seemed to lack the relatively slow fluctuations that were apparent in the record with $0.3 \mu \mathrm{M}$. This impression was confirmed by refiltering the records at a lower bandwidth to eliminate the higher-frequency fluctuations and emphasize the contribution of slower variations. Filtered with a corner frequency of $100 \mathrm{~Hz}$, the increase in

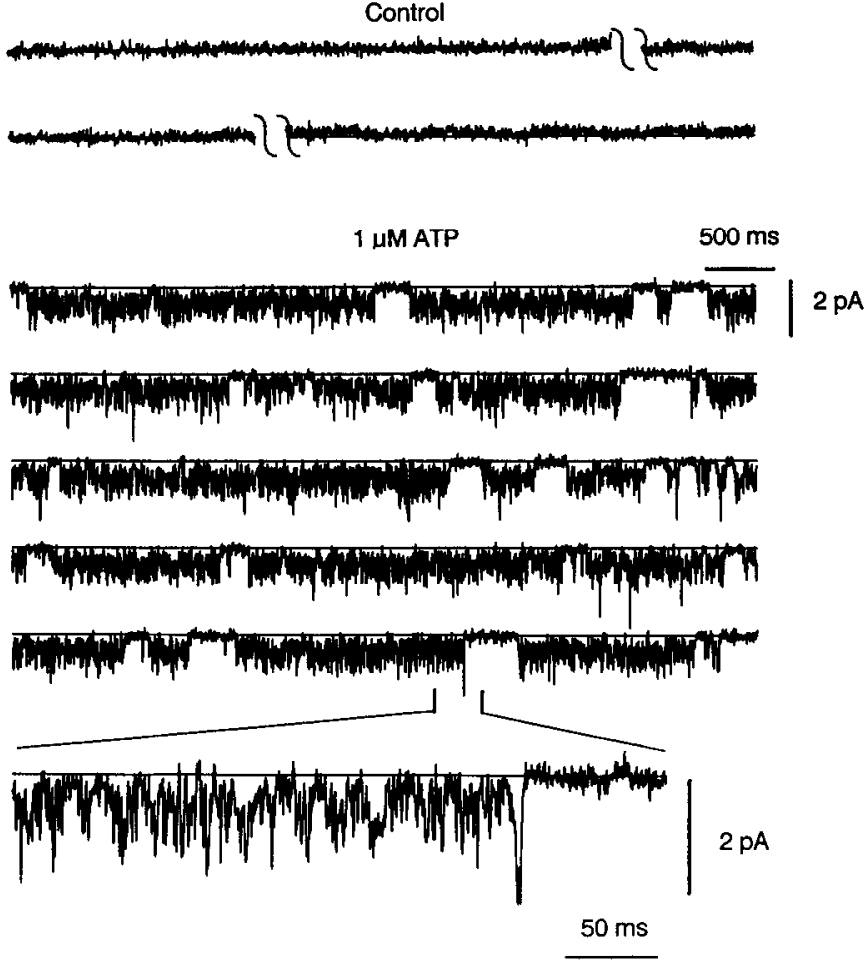

Figure 8. Single-channel activity evoked by $1 \mu \mathrm{M} \mathrm{ATP}$ applied to an outside-out patch from a bullfrog DRG neuron. Holding potential -100 $\mathrm{mV}$. There was no channel activity in the absence of ATP; two sections of the control record are omitted where there were electrical artifacts from solution outflow. The lower traces are a continuous recording of about $27 \mathrm{sec}$ in the presence of ATP, beginning about $20 \mathrm{sec}$ after the patch was moved into ATP-containing solution. Current was filtered at $1 \mathrm{kHz}(-3 \mathrm{~dB}, 8$-pole Bessel) and sampled every $100 \mu \mathrm{sec}$ (but only every 25 th point is plotted in the figure). Cs-glutamate internal solution, Tyrode's solution externally. Cell W21B, $35 \mu \mathrm{m}$.

variance was actually smaller during the larger current elicited by $100 \mu \mathrm{M}$ ATP than during the current elicited by $0.3 \mu \mathrm{M}$.

Although the results of noise analysis on bullfrog and rat neurons were fairly similar, values of estimated unitary current were systematically greater in rat neurons than in bullfrog neurons studied under the same conditions. Thus, in experiments on rat neurons with internal Cs-glutamate solution and external Tyrode's solution, the variance/mean averaged $1.0 \pm 0.9 \mathrm{pA}(n$ $=4$ ), determined at potentials of -80 or $-90 \mathrm{mV}$ using $0.3-$ $1.2 \mu \mathrm{M}$ ATP (with currents filtered at $3 \mathrm{kHz}$ ). Under the same conditions in bullfrog neurons, the variance/mean averaged 0.56 $\pm 0.05 \mathrm{pA}$ at $-80 \mathrm{mV}(n=4)$ and $0.64 \pm 0.09 \mathrm{pA}$ at -100 $\mathrm{mV}(n=6)$.

\section{Patch recordings}

We attempted to record single-channel activity by exposing outside-out patches to ATP. We confined our attempts to bullfrog neurons, since the desensitization in rat neurons seemed likely to limit the experiments that could be done with channels from these cells. The ionic conditions were the same as in most of the whole-cell recordings, with an external solution of normal Tyrode's and an internal solution containing mainly Cs-glutamate. Under these conditions, many outside-out patches showed spontaneous channel activity in the absence of ATP, and these patches were discarded. (We made no attempt to study this spontaneous activity, whose characteristics varied greatly, but 


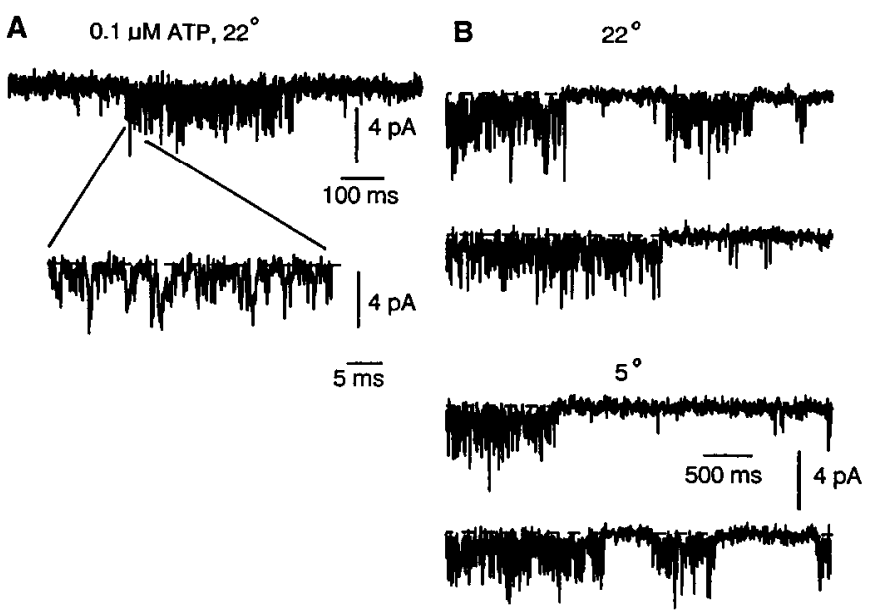

Figure 9. Flickering of single-channel currents with wideband recording and at low temperature. $A$, Single-channel events at $-110 \mathrm{mV}$ recorded in $\mathrm{Mg}$-free external solution with a corner frequency $(-3 \mathrm{~dB})$ of $6 \mathrm{kHz}$. Lower trace shows a section of current at higher time resolution (sampling interval $60 \mu \mathrm{sec}$ ). Internal solution: $\mathrm{Mg}$-free Cs-glutamate solution; external solution (in mM): $160 \mathrm{NaCl}, 2 \mathrm{CaCl}_{2}, 10 \mathrm{HEPES} \mathrm{(pH}$ 7.4 with $\mathrm{NaOH}$ ). Patch $\mathrm{K} 07 \mathrm{C}$. $B$, Single-channel events at $-110 \mathrm{mV}$ activated by $0.1 \mu \mathrm{M}$ ATP, recorded at $22^{\circ} \mathrm{C}$ (top 2 traces) and $5^{\circ} \mathrm{C}$ (bottom 2 traces). Filtered with a corner frequency of $3 \mathrm{kHz}(-3 \mathrm{~dB}$, Bessel). Internal and external solutions as in $A$. Patch K08B.

in no case did the activity resemble that induced by ATP in other patches.) Of 57 patches in which stable, quiet recordings could be made and which had no channel activity in the absence of ATP, 13 responded to ATP with channel activity. Figure 8 shows channel activity produced by application of ATP to one such patch, held at $-100 \mathrm{mV}$. After recording from the patch for several minutes in the control solutions, during which there was no channel activity, an external solution containing $1 \mu \mathrm{M}$ ATP was applied to the patch and channel activity was induced. Short silent periods were interspersed among long bursts of channel activity. During the bursts, the current fluctuated rapidly (around a mean of about $0.7 \mathrm{pA}$ ). The fluctuations were so rapid that there were never well-resolved channel openings lasting long enough to measure. There were occasional spikes of current as large as $2 \mathrm{pA}$, one of which can be seen in a stretch of channel activity shown at a faster time base in the lower panel of the figure. The records are suggestive of a single channel that when fully open carries a current of $2 \mathrm{pA}$ or more but which opens and closes so rapidly that individual opening and closing events are not resolved at this bandwidth (corner frequency, 1 $\mathrm{kHz}$ ).

It seemed possible that the rapid flickering in the single-channel currents arose from flickery block by external or internal $\mathrm{Mg}$ ions, so recordings were made using $\mathrm{Mg}$-free solutions internally and externally. However, the flickering of the single channels persisted under these conditions (Fig. 9). Even when the corner frequency with which the signal was filtered was increased to $6 \mathrm{kHz}$, it still was impossible to clearly resolve full openings of the channel (Fig. 9A). The flickering behavior of the channel also persisted when patches were cooled to $5^{\circ} \mathrm{C}$ (Fig. 9B).

Figure 10 shows records from an experiment in which another patch (held at $-130 \mathrm{mV}$ ) was exposed to $100 \mu \mathrm{M} \mathrm{ATP}$, which according to the dose-response experiments described in the previous paper is a nearly saturating concentration. Application

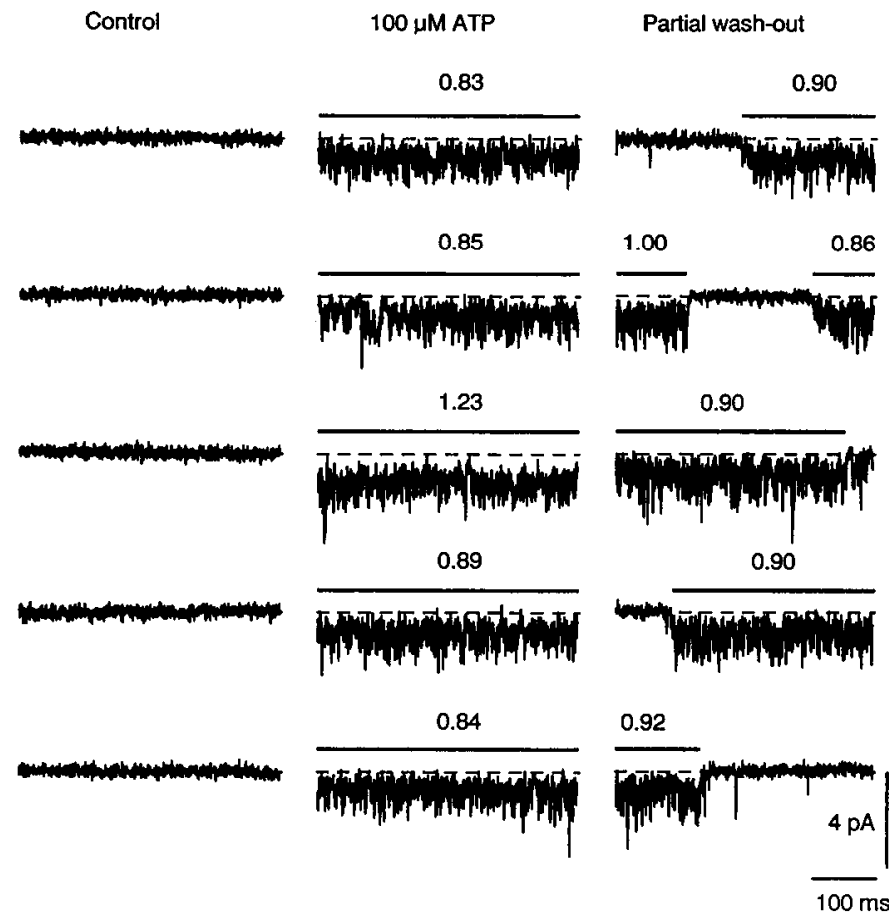

Figure 10. Single-channel activity in high and low ATP concentrations. Holding potential $-130 \mathrm{mV}$. An outside-out patch was formed from a bullfrog neuron. There was no channel activity in the absence of ATP (left panels). Addition of $100 \mu \mathrm{M}$ ATP (bath applied) elicited a fluctuating inward current with a mean of about $0.9 \mathrm{pA}$ (middle panels). Current traces show $400 \mathrm{msec}$ segments recorded every second; numbers above each trace give mean current during trace. After rinsing with about 10 bath volumes of ATP-free solution, the traces right were recorded. Numbers above traces give mean current during indicated burst. Filtered at $1 \mathrm{kHz}(-3 \mathrm{~dB}, 8$-pole Bessel), sampled every $400 \mu \mathrm{sec}$. Csglutamate internal solution, Tyrode's solution externally. Cell W01I.

of $100 \mu \mathrm{M}$ ATP induced what appeared to be a continuous burst of current, like those in Figure 8 but without the periods of silence seen at the lower concentration. To see how the channel activity would change in the same patch exposed to lower ATP concentrations, the ATP (which in this case was applied in the bath solution) was progressively lowered by rinsing the bath with ATP-free solution. After rinsing with about 10 bath volumes of ATP-free solution (which based on other dilution experiments would be expected to decrease the ATP concentration by roughly a factor of several hundred or so), the channel activity changed. Now, bursts of current were interspersed with silent periods, as with $1 \mu \mathrm{M}$ ATP in Figure 8 . The current during the bursts appeared nearly identical to that permanently activated by $100 \mu \mathrm{M}$ ATP. As shown in the figure, the mean current during bursts after partial washout of ATP (shown above the current records) was nearly identical to the mean current activated by $100 \mu \mathrm{M}$ ATP. A reasonable interpretation is that there was a single channel present in this patch. When fully activated by $100 \mu \mathrm{M}$ ATP, the channel flickered continually around a mean current of $0.9 \mathrm{pA}$, while with submaximal ATP these periods of flickery activity were interspersed with periods of complete closure. Higher concentrations of ATP evidently place the channel in the activated, flickery condition more of the time, but the behavior of the channel while in this condition does not seem to change with ATP concentration.

Figure 11 shows the voltage dependence of the ATP-induced 
$-170 \mathrm{mV}$
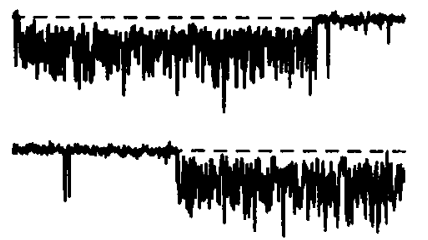

$-150$
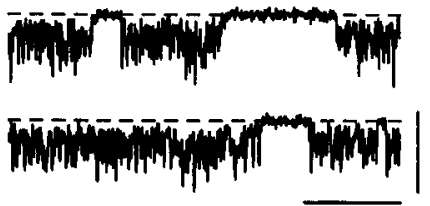

$100 \mathrm{~ms}$

$-130$

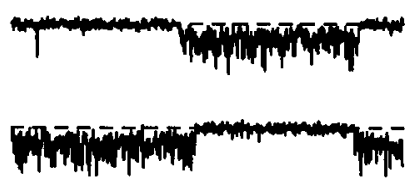

Figure 11. Voltage-dependence of single-channel current. Same patch as in Figure 10. Traces were recorded at various steady holding potentials after partial wash-out of $100 \mu \mathrm{M}$ ATP as described in Figure 10.

current. The rapidly fluctuating character of the current during bursts was evident at all membrane potentials. The size of the current during the bursts decreased as the membrane potential was made more positive. No channel activity was resolvable positive to $-50 \mathrm{mV}$; in this patch, the membrane potential was changed in $20 \mathrm{mV}$ increments up to $+50 \mathrm{mV}$ with no channel activity resolvable between -50 and $+50 \mathrm{mV}$. However, when the potential was returned to $-130 \mathrm{mV}$ following this series there was no longer channel activity, so the channel may have irreversibly desensitized or otherwise disappeared during this sequence. This also happened in another patch: holding at positive potentials for a minute or so resulted in the irreversible loss of channel activity. We were also unable to resolve clear outward ATP-activated events in experiments in which depolarizing pulses to $+60-+100 \mathrm{mV}$ were given from a negative membrane potential; irregular channel activity at very positive potentials in the absence of ATP obscured possible ATP-activated events. Figure 12 shows the mean current during bursts as a function of membrane potential. The burst current-voltage relation is nonlinear, showing the same curvature that is characteristic of the inwardly rectifying whole-cell current.

\section{Discussion}

\section{Ionic selectivity}

The conductance activated by ATP is clearly highly selective for cations over anions, since substitution of NMDG for $\mathrm{Na}, \mathrm{K}$ and $\mathrm{Mg}$ - with no changes in internal or external anions-reduces the inward current by more than $97 \%$ (Fig. 4). The permeability of NMDG, if any, is far smaller than that of $\mathrm{Na}$. This result fits well with the report that substitution of Tris or tetraethylammonium ions for external $\mathrm{Na}$ greatly diminishes the inward current activated by ATP (Krishtal et al., 1983). The reversal potential near $0 \mathrm{mV}$ with normal Tyrode's outside and either $\mathrm{K}$ or $\mathrm{Cs}$ as the main internal cation implies that $\mathrm{Na}, \mathrm{Cs}$, and $K$ are nearly equally permeable.

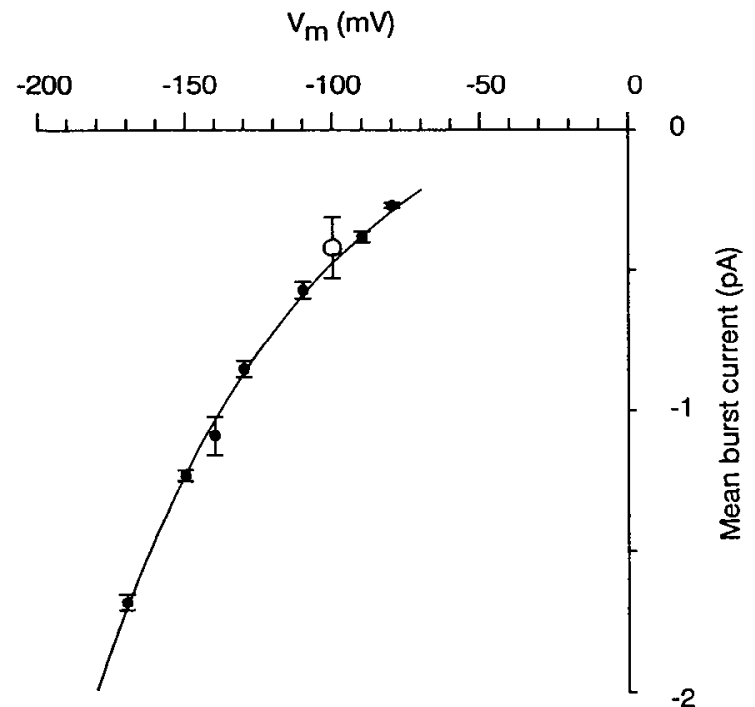

Figure 12. Mean burst current as a function of membrane potential. Mean current was determined during bursts in the experiment of Figures 10 and 11. Each point (filled circles) represents mean \pm SEM of average current during 4-10 long bursts. Open circle represents mean \pm SEM for unitary current estimated in 6 cells by fluctuation analysis of wholecell current filtered at $100 \mathrm{~Hz}$; in each case, unitary current was estimated from the ratio of variance to mean current elicited by application of $0.3-1.2 \mu \mathrm{M}$ ATP at $-100 \mathrm{mV}$.

Our results show that $\mathrm{Ca}$ is permeant in the ATP-activated channel, though less so than $\mathrm{Na}$. The calculated permeability ratio of $P_{\mathrm{Ca}} / P_{\mathrm{Na}}$ of 0.3 is very close to that for the $\mathrm{ACh}$ receptor channel in the muscle end-plate (Lewis, 1978; Adams et al., 1980). Based on the evidence so far, the ATP-activated channel may have a permeation pathway basically similar to that of the end-plate channel, strongly selective against anions but having a nonselective permeability to small cations (see Adams et al., 1980; Dwyer et al., 1980). However, the strong inward rectification of the ATP-activated channel is a distinguishing feature.

The rectification is instantaneous with a resolution of $10 \mathrm{~s}$ of microseconds. This is consistent with the rectification being a property of ion permeation in the channel. However, since the flickery behavior of the channel implies that there are gating processes occurring on a time scale of $10 \mathrm{~s}$ of microseconds, the rectification could also arise from voltage-dependent gating processes (see below).

\section{Single-channel behavior}

The single-channel recordings show that the ATP-activated current arises from discrete channels. Because the channels flicker so rapidly when activated that there were no well-resolved full openings, it is impossible to assign a conductance to the channels. Even with ATP at $100 \mu \mathrm{M}$, which from the whole-cell experiments described in the previous paper is known to be a saturating concentration, a channel spends only a small fraction of the time open, since mean current through the channel is only a fifth or so of the maximal current reached during occasional spikes. The simplest interpretation of the single-channel experiments is that a channel undergoes a rather slow gating process-dependent on ATP concentration-between being closed or activated and that at high ATP a channel is in the activated state nearly all the time but that-regardless of the ATP concentration - an "activated" channel always flickers rap- 
idly, on a time scale of microseconds, between open and closed states, spending only $20 \%$ or so of the time in the open state. This interpretation is expressed in the model given in the previous paper (Fig. 9). Whether the flickering behavior is really so simple as a first-order transition between single closed and open states remains to be tested by more quantitative treatment of the current fluctuations in an activated channel. In any case, the opening and closing events underlying the flickering must take place on a time scale at least as fast as 10 s of microseconds since distinct openings could not be resolved even when recording with a bandwidth of $6 \mathrm{kHz}$ (Fig. 9).

An interesting possibility is that the rectification of the ATPactivated currents could arise from voltage-dependence of the gating processes underlying flickering, which (as required by the results of Fig. 3) would be expected to relax within $10 \mathrm{~s}$ of microseconds. Specifically, "flickering rate constants" ( $\alpha$ and $\beta$ in the model in Fig. 9 of the previous paper) that were voltage dependent in such a way that an activated channel spends less time in the open state at depolarized potentials would fit with the existence of inward rectification, the difficulty in resolving outward single-channel events, and the faster decay of wholecell currents at depolarized potentials (since the effective rate constant for decay is $3 k_{\text {off }}[\alpha /(\alpha+\beta)]$ ). (However, voltage dependence of the flickering rate constants would produce only small voltage-dependent changes in ATP's potency and alone probably could not explain all the voltage dependent effects described in the last paper.)

There is excellent correspondence between the single-channel behavior in patches and properties of the whole-cell currents. The single-channel current-voltage curve shows a curvature very similar to that of the whole-cell currents. Also, the whole-cell noise behaves exactly as expected from a current arising from the summation of many channels behaving as in the singlechannel recordings. Such channels would give rise to $2 \mathrm{com}$ ponents of noise: relatively low frequency fluctuations due to the slow gating between closed and activated states and relatively high frequency fluctuations from the flickering of activated channels. At low ATP concentrations, there would be be both low- and high-frequency components of the noisc. However, at high ATP concentrations, channels would be in the activated state almost all the time and there would be little contribution of low-frequency fluctuations. Exactly this pattern was seen in the experiment shown in Figure 7, where the lowfrequency noise is actually smaller with an ATP concentration of $100 \mu \mathrm{M}$ than with $0.3 \mu \mathrm{M}$, despite the 10 times larger current activated by $100 \mu \mathrm{M}$ ATP.

Quantitatively, too, the fluctuation analysis results fit well with the single-channel recording. The average estimate of unitary current at $-100 \mathrm{mV}$ from noise analysis was $0.64 \mathrm{pA}$, which is quite similar to the mean current during a bout of flickering in the single-channel recordings at similar potentials (Figs. 11, 12). For comparison with the mean current during a burst of flickery opening, the most appropriate value would be the unitary current from noise analysis of a fairly heavily filtered signal, since a heavily filtered single-channel record would have an effective open channel current equal to the mean current during flickering. For this comparison, noise analysis was done on wholecell records that were refiltered with a corner frequency of 100 $\mathrm{Hz}(-3 \mathrm{~dB}, 8$-pole Bessel) rather than the usual $3 \mathrm{kHz}$. As expected (see Fig. 7), the unitary currents from noise analysis are somewhat smaller when calculated from the more heavily filtered signals, with an average value of $0.42 \pm 0.11 \mathrm{pA}(n=$
6) at $-100 \mathrm{mV}$. As shown in Figure 12, this value from fluctuation analysis is nearly identical to the mean burst current measured directly from the single-channel recordings. There thus seems little doubt that the whole-cell ATP-induced current really does arise from the summed activity of many channels like those in the single-channel recordings.

The single-channel current can be used to estimate the number of ATP-activated channels present in the cells. At $-80 \mathrm{mV}$, the mean current during a burst was $0.3 \mathrm{pA}$. The average current activated by $100 \mu \mathrm{M}$ ATP at this potential in whole-cell experiments was $1935 \mathrm{pA}$, which would correspond to 6450 channels per cell. Assuming an average cell capacitance of $25 \mathrm{pF}$ and a specific capacitance of $1 \mu \mathrm{F} / \mathrm{cm}^{2}$, this corresponds to about 3 channels $/ \mu \mathrm{m}^{2}$ of membrane.

While this paper was being prepared, Krishtal et al. (1988) described recordings of single ATP-activated channels in patches from rat sensory neurons. The channels in rat neurons are similar to those we recorded in bullfrog neurons in showing flickering when open and having a strongly rectifying current-voltage characteristic. However, the flickering of the channels in rat neurons seems less pronounced than in bullfrog neurons, so that a more clearly defined fully open state could be defined. The average current during a flickery period is also greater in the rat channels recorded by Krishtal et al. than in bullfrog neurons, which fits well with the larger value of unitary current in rat neurons that was suggested by our noise-analysis experiments; the value of $1 \mathrm{pA}$ at -80 to $-90 \mathrm{mV}$ that we estimated using fluctuation analysis on rat neurons is about $30-40 \%$ smaller than the unitary currents measured directly by Krishtal et al. with similar external solutions. A reasonable hypothesis is that the ATP-activated channels in bullfrog and rat neurons have very similar unitary properties, differing primarily in the degree of flickering. It may be that a fully open channel would have the same conductance in the 2 species but that due to more flickering in the bullfrog channel the channel spends less time open when activated.

\section{Comparison with other ATP-activated channels}

The ATP-activated current in sensory ncurons resembles that in vas deferens smooth muscle (Nakazawa and Matsuki, 1987; Friel, 1988), rabbit ear artery smooth muscle (Benham and Tsien, 1987; Benham et al., 1987), atrial muscle (Friel and Bean, 1988), and cultured chick skeletal muscle (Hume and Honig, 1986) in being a cationic current with a reversal potential near $0 \mathrm{mV}$. However, it seems clear that there are major differences between the channels carrying the current in the various cell types. The pronounced inward rectification seen in sensory neurons is also present in vas deferens smooth muscle (Friel, 1988) but not in atrial muscle cells, where the current-voltage relationship is nearly linear (Friel and Bean, 1988). The current-voltage relation in rabbit ear artery cells is concave at negative potentials (Benham and Tsien, 1987), like that in sensory neurons, but, unlike sensory neurons, the conductance in these smooth muscle cells is capable of carrying outward currents nearly as large as inward currents (D. D. Friel, personal communication).

The unitary current size varies widely among the preparations. Noise-analysis experiments suggest that the unitary current is very small $(\sim 0.05 \mathrm{pA}$ at $-130 \mathrm{mV})$ in cardiac atrial muscle (Friel and Bean, 1988), and it is probably at least as small in cultured skeletal muscle (Hume and Honig, 1986). However, both noise analysis and direct single-channel recording show that the unitary current size is much larger in vas 
deferens muscle (Nakazawa and Matsuki, 1987; Friel, 1988), rabbit ear artery muscle (Benham and Tsien, 1987), and sensory neurons (Krishtal et al., 1988). It also already seems clear that even these 3 preparations with high unitary conductances have channels with different ion-permeation pathways. The unitary current in divalent-free solutions is about 7 times higher in sensory neurons $(\sim 7 \mathrm{pA}$ at $-100 \mathrm{mV}$; Krishtal et al., 1988) than in rabbit ear artery smooth muscle cells $(\sim 1 \mathrm{pA}$; Benham and Tsien, 1987), and the channels in sensory neurons seem to be blocked by lower concentrations of $\mathrm{Ca}$ (Benham and Tsien, 1987; Krishtal et al., 1988). Another indication of different ionpermeation pathways is the contrast between Benham and Tsien's (1987) estimate of $P_{\mathrm{Ca}} / P_{\mathrm{Na}}$ of about 3 in vascular muscle and our estimate of 0.3 in sensory neurons.

\section{Comparison with other ligand-gated channels}

As already noted, the ion-permeation pathway in the ATPactivated channel of sensory neurons may be generally similar to that of the end-plate ACh-activated channel (Adams et al., 1980; Dwyer et al., 1980) and perhaps to those of channels in central neurons gated by glutamate (Vylicky et al., 1988) that are also relatively non selective between small cations like $\mathrm{Na}$, $\mathrm{K}$, and $\mathrm{Cs}$, but are relatively impermeable to large organic cations.

The ion-permeation pathway in ATP-activated channels may also be similar to that of the light-sensitive, cGMP-activated channels in rods. These also pass small monovalent cations without much selectivity, are impermeable to large organic cations, and can carry sizable current with external solutions consisting mainly of Ca (e.g., Hodgkin et al., 1985; Menini et al., 1988). There is also a striking similarity between the gating kinetics of the ATP-activated channels in sensory neurons and those of the cGMP-activated channels in rods (Matthews and Watanabe, 1988). Like the ATP-activated channel, the cGMPactivated channel shows rapid, continual flickering when in an activated state. This similarity in gating, together with similarities in ligand stoichiometry and selectivity, suggests that these 2 nucleotide-activated channels may be related.

\section{Physiological significance}

The physiological role of ATP-activated channels in sensory neurons is unknown. ATP sensitivity was found by Krishtal et al. (1983) for neurons in nodose, vestibular, and trigeminal ganglia (see also Salt and Hill, 1983), in addition to DRG neurons. It seems reasonable to assume that the ATP-activated channels found in cell bodies reflect those present on terminals of the cells. It is possible that ATP is released as a transmitter by primary receptor cells to excite the afferent terminals of some sensory neurons. Another possibility is that some nociceptors are excited when ATP is released into the extracellular fluid from damaged tissue. As noted by Krishtal et al. (1988), the inward rectifying property of the ATP-activated channels makes them well-suited for exciting a neuron without shunting the action potentials that are generated. In addition to primary and secondary sensory neurons, some spinal cord neurons can be excited by ATP (Jahr and Jessell, 1983; Fyffe and Perl, 1984). It will be interesting to see if the ATP-sensitive channels in central neurons are similar to those in sensory neurons.

\section{References}

Adams, D. J., T. M. Dwyer, and B. Hille (1980) The permeability of endplate channels to monovalent and divalent metal cations. J. Gen. Physiol. 75: 493-510.

Bean, B. P., C. A. Williams, and P. W. Ceelen (1988) ATP-activated channels in rat and bullfrog sensory neurons. Soc. Neurosci. Abstr. 14: 1045 .

Benham, C. D., and R. W. Tsien (1987) A novel receptor-operated $\mathrm{Ca}^{2+}$-permeable channel activated by ATP in smooth muscle. Nature 328: 275-278.

Benham, C. D., T. B. Bolton, N. G. Byrne, and W. A. Large (1987) Action of externally applied adenosine triphosphate on single smooth muscle cells from rabbit ear artery. J. Physiol. (Lond.) 387: 473-488.

Dwyer, T. M., D. J. Adams, and B. Hille (1980) The permeability of the end-plate channel to organic cations in frog muscle. J. Gen. Physiol. 75: 469-492.

Fatt, P., and B. L. Ginsborg (1958) The ionic requirements for the production of action potentials in crustacean muscle fibres. J. Physiol. (Lond.) 142: 516-543.

French, R. J., and J. B. Wells (1977) Sodium ions as blocking agents and charge carriers in the potassium channel of the squid giant axon. J. Gen. Physiol. 70: 707-724.

Friel, D. D. (1988) An ATP-sensitive conductance in single smooth muscle cells from the rat vas deferens. J. Physiol. (Lond.) 401: 361380.

Friel, D. D., and B. P. Bean (1988) Two ATP-activated conductances in bullfrog atrial cells. J. Gen. Phyiol. 91: 1-27.

Fyffe, R. W., and E. R. Perl (1984) Is ATP a central synaptic mediator for certain primary afferent fibers from mammalian skin? Proc. Natl. Acad. Sci. USA 81: 6890-6893.

Hille, B. (1975) Ionic selectivity of $\mathrm{Na}$ and $\mathrm{K}$ channels of nerve membranes. In Membranes: A Scries of Advances, Vol. 3, G. Eisenman, ed., pp. 255-323, Marcel Dekker, New York.

Hodgkin, A. L., P. A. McNaughton, and B. J. Nunn (1985) The ionic selectivity and calcium dependence of the light-sensitive pathway in toad rods. J. Physiol. (Lond.) 358: 477-468.

Hume, R. I., and M. G. Honig (1986) Excitatory action of ATP on embryonic chick muscle. J. Neurosci. 6: 681-690.

Jahr, C. E., and T. M. Jessell (1983) ATP excites a subpopulation of rat dorsal horn neurons. Nature 304: 730-733.

Krishtal, O. A., S. M. Marchenko, and V. I. Pidoplichko (1983) Receptor for ATP in the membrane of mammalian sensory neurones. Neurosci. Lett. 35: 41-45.

Krishtal, O. A., S. M. Marchenko, and A. G. Obukhov (1988) Cationic channels activated by extracellular ATP in rat sensory neurons. Neuroscience 27: $995-1000$.

Lewis, C. A. (1978) Ion-concentration dependence of the reversal potential and the single channel conductance of ion channels at the frog neuromuscular junction. J. Physiol. (Lond.) 286: 417-455.

Marty, A. (1983) Blocking of large unitary calcium-dependent potassium currents by internal sodium ions. Pfluegers Arch. 396: 179-181.

Matthews, G., and S.-I. Watanabe (1988) Activation of single ion channels from toad rod inner segments by cyclic GMP: Concentration-dependence, J. Physiol. (Lond.) 403: 389-405.

Menini, A., G. Rispoli, and V. Torre (1988) The ionic selectivity of the light-sensitive current in isolated rods of the tiger salamander. J. Physiol. (Lond.) 402: 279-300.

Nakazawa, K., and N. Matsuki (1987) Adenosine triphosphate-activated inward current of isolated smooth muscle cells from rat vas deferens. Pfluegers Arch. 409: 644-646.

Neher, E., and C. F. Stevens (1977) Conductance fluctuations and ionic pores in membranes. Annu. Rev. Biophys. Bioeng. 6: 345-381.

Salt, T. E., and R. G. Hill (1983) Excitation of single sensory neurons in the rat caudal trigeminal nucleus by iontophoretically applied adenosine 5'-triphosphate. Neurosci. Lett. 35: 53-57.

Vylicky, L., J. Krusek, and C. Edwards (1988) Differences in the pore sizes of the N-methyl-D-aspartate and kainate cation channels. Neurosci. Lett. 89: 313-318. 